\title{
The Determinants of Contract Length in Temporary Help Employment
}

\author{
Tommaso Nannicini * \\ UNIVERSIDAD CARLOS III DE MADRID
}

This version: November 30, 2005

\begin{abstract}
This paper investigates the determinants of labor contract duration in the case of temporary help employment. A simple theoretical model is developed, in order to depict the choice of contract length made by a firm that recruits temporary agency workers to deal with activity peaks. Assuming that the hiring of a new worker is associated with selection and training costs, longer contracts have an option value in face of a greater persistence of positive shocks. The model has two testable implications. First, the degree of serial correlation in market demand positively affects contract length. Second, the shortage of alternative employment opportunities negatively affects contract length. Using data on Italian temporary agency workers, both implications are confirmed by the econometric analysis.
\end{abstract}

JEL Classification: J2, J6.

Keywords: temporary work agencies, contract length, clustering.

*I would like to thank "Manpower Italia" for allowing me to use its personnel data set. Many thanks also to Andrea Ichino, Samuel Bentolila, Juan Dolado, Mathias Thoenig, participants at the XVII AIEL Conference, lunch seminar participants at EUI and MIT for their insightful comments. An anonymous referee provided very helpful suggestions for improving the paper. All errors are mine. Address correspondence to: Universidad Carlos III, Department of Economics, C/ Madrid 126, Getafe (Madrid), Spain. Email: tommaso.nannicini@uc3m.es. 


\section{Introduction}

During the 1990s, Temporary Help Employment (THE, henceforth) ${ }^{1}$ widely expanded in developed countries. It rapidly grew where it was already used and was liberalized where it was previously forbidden. Even though it maintains a small absolute incidence over the stock of total employees at any point in time, this non-standard contract is now a common experience of a large number of individuals, because of the high turnover of workers employed in similar positions. Many issues concerning THE have been analyzed in theoretical and empirical works: the reasons why it is used; the factors explaining its recent growth in different environments; the characteristics of workers who select themselves into this relationship; the transition from temporary to permanent employment. ${ }^{2}$

One issue that has remained unexplored concerns the determinants of contract length in this employment relationship. Segal and Sullivan (1997a) use US administrative data to study the duration of job spells in the THE industry, but they do not investigate what affects the length of the assignments. This paper focuses on the determinants of the desired contract duration, and particularly on the relationship between contract length and the persistence/volatility of the process of market demand. Focusing on this issue is interesting per se and, in addition, it sheds light on the welfare effects of THE, since contract duration turns out to be a good proxy of the "precariousness" of temporary agency workers (as discussed below).

\footnotetext{
${ }^{1}$ This expression refers to a triangular contract, in which an agency hires a worker for the purpose of placing her/him at the disposal of a using firm for a short-term assignment.

${ }^{2}$ See -among others- Segal and Sullivan (1997a, 1997b), Estevao and Lach (1999), Houseman (2001) and Autor (2001, 2003) about the US; Russo, Gorter and Moolenaar (1997), Lechner et al. (2001), Malo and Munoz-Bullon (2002), Montanino and Sestito (2003), Kvasnicka (2005) and Ichino, Mealli and Nannicini (2005) about European countries. See OECD (2002), and Houseman and Osawa (2003) for general surveys.
} 
The Italian labor market is the reference case, but the results might have a general scope. In Italy, THE was recently liberalized (see law 196/1997) ${ }^{3}$ and firms have started using temporary workers (temps, henceforth) extensively, especially in the manufacturing sector. ${ }^{4}$ The liberalization of THE immediately triggered a stormy policy debate over the risk of establishing a "dual labor market". In a dual labor market, regular jobs (with long-term contracts, higher wages and union protection) coexist with precarious jobs (with short-term contracts, lower wages and no access to benefits tied to length of service). This phenomenon can arise from different dynamics: efficiency-wage arguments, which lead firms to grant security to primary employees and use secondary workers to deal with fluctuations in demand (Saint-Paul, 1996); diverging paths of regulation for standard and non-standard contracts; flux and uncertainty, which adhere in the economic system and unevenly influence factors of production or different groups of workers (Piore, 1980). If the liberalization of THE reinforced (or even created) a similar phenomenon in Italy, one should observe that temps are primarily used in more volatile sectors and are more precarious (i.e., receive shorter assignments and experience a lower probability to find a permanent job) exactly in those sectors.

Nannicini (2004) estimates the average utilization of THE by economic sector and finds that the utilization rate is positively correlated with production volatility. It might still be the case, however, that in more volatile sectors temporary workers receive longer assignments and/or end up attain-

\footnotetext{
${ }^{3}$ The Italian law forbids firms to use temporary contracts in the following cases: replacement of workers on strike; firms that made collective dismissals in the last 12 months; jobs that require medical vigilance; firms that are experiencing a time-of-work reduction. Collective agreements stipulate that temporary workers cannot exceed $8-15 \%$ of total employees (depending on the sector), and fix the allowed motivations for using them (peak activity; one-off work; expertise not available within the firm). Firms cannot extend an individual contract for a cumulated period longer than 24 months.

${ }^{4}$ See Ministero del lavoro (2000) and Isfol (2001) for an aggregate picture of the take-off of THE in Italy.
} 
ing a stable job with greater probability. In this respect, contract duration seems indeed a good proxy of the precariousness of temps. According to the finding by Montanino and Sestito (2003) about THE in Italy, contract length is positively correlated with the probability to get a stable job. ${ }^{5} \mathrm{~A}$ three-month increase of contract duration (equal to its standard deviation) enhances the probability to get a permanent job by 8 percentage points (the average probability being equal to $34 \%$ ). This positive association may be due to a "screening" function of THE, or to the fact that workers with longer assignments have a greater probability to be employed in the firm when a permanent vacancy arises. Moreover, according to the sample used in this paper, in the case of temps who do not achieve a permanent position and go through repeated assignments, the length of the first contract is positively associated to the average length of future contracts (with a correlation coefficient equal to 0.7). At the end of the day, in order to assess the relative precariousness of temps in different sectors of the economy, it is crucial to understand the factors that determine the duration of temporary contracts.

The structure of the paper is as follows. In Section 2, the conflicting findings of the theoretical literature on labor contract length are briefly reviewed. Section 3 presents a rudimentary theoretical model, which captures the relevant trade-off in the firm's choice of THE contract length. Section 4 tests the main predictions of the model. The econometric analysis makes use of the Italian data set of "Manpower", one of the main companies in the recently born Italian THE market. Section 5 draws some conclusions.

\footnotetext{
${ }^{5}$ More precisely, Montanino and Sestito (2003) find a reverse U-shaped relationship: contract duration firstly enhances and then decreases the probability to find a stable job. However, the peak of this relationship is equal to 274 days (against an average duration of 73 days). In the sample used in this paper, only $5 \%$ of total observations show a longer duration. Hence, the effect of contract length can be considered as positive.
} 


\section{Theoretical Literature on Contract Length}

There is a rich theoretical literature on the determinants of desired contract durations, leading to conflicting predictions about the impact of uncertainty and volatility on contract length. The early contributions emphasize that volatility is negatively related to contract length, whereas contracting costs positively affect duration. Gray (1978) concludes that "increased variability -regardless of source- shortens contract length". Similarly, the effect of increased contracting costs on contract length is positive. These implications arise from two basic ingredients: a transaction-cost argument and an efficient-production argument. The former emphasizes that longer contracts lower the losses due to transaction costs. The latter stresses that shorter contracts reduce the expected losses due to inefficient production and employment. This is true because these expected losses increase with the deviation of the actual real wage from the real wage that would equate the demand and supply of labor, and such a deviation is greater for more distant periods as uncertainty rises over time. Dye (1985) builds a model which tries to overcome some of the limitations of Gray's approach, finding the same theoretical implications about uncertainty and contracting costs.

More recent models, however, stress that volatility may have a positive effect on contract length under some circumstances. Harris and Holmstrom (1987) find such a result using an information-cost argument. They develop a model where recontracting occurs when the parties find it profitable to update their information and pay the associated cost. In this setting, contract length is the period between costly observations of the underlying state process. Contracts may increase their duration with a greater uncertainty since, with a noisier process, costly information is less valuable. More precisely, 
Harris and Holmstrom's analysis leads to a U-shaped effect of the variability of the state process on contract duration: when the process is less volatile, contract length decreases with noisiness; on the contrary, when the process is more volatile, contract length increases with noisiness. Danziger (1988) uses an efficient-risk-sharing argument while showing a positive association between uncertainty and contract duration. A long-term labor relationship can provide insurance against aggregate negative shocks for risk-averse workers. The larger the aggregate variability, the greater the value attached to the insurance protection delivered by longer contracts.

Empirical studies on the relationship between volatility and labor contract length find mixed results (Vroman, 1989; Wallace and Blanco, 1991; Murphy, 1992), failing to establish any consistent evidence about the role of uncertainty in shaping the duration of contracts.

However, it should be noted that all the above studies fit well with the bargaining process of standard employment (where contracts are expected to be open-ended, and are signed in a structured and unionized setting), while contracts in THE are likely to respond to different motivations and incentives. Particularly, since those contracts are often signed when the firm's activity is above its normal level, the persistence of positive demand shocks (and not only their probability to show up in the first place) can be expected to play a crucial role. In the next section, a simple model of the choice of contract length in THE is developed. In a sense, this model leads to a conclusion similar to the one by Harris and Holmstrom (1987) and Danziger (1988), because of an option-value argument: if the hiring of a new temp is related to an initial cost due to selection or training, longer contracts have an option value in the presence of greater persistence (and, possibly, volatility). 


\section{A Simple Model}

The following model is an attempt to depict the choice of THE contract length, made by a firm that wants to hire a temporary agency worker in order to face a non-permanent increase in market demand. This does not mean that flexibility is the only rationale for hiring contingent employees. However, according to surveys among firms, this is the most important motivation. When asked why they make use of temporary workers, firms usually give two types of answer: (1) organizational or business-cycle flexibility; (2) screening or personnel selection. ${ }^{6}$ The peak-in-demand rationale is always the most cited reason and deserves particular attention when addressing the issue of contract length, which is a decision strictly linked to the original motivation of the contract. Incidentally, it should be noticed that flexibility and screening are not necessarily substitute motivations, since in many cases they may complement each other. For example, a firm might hire a temp to face a positive shock and decide later to use the same worker (already screened during the short-term assignment) to fill a permanent vacancy.

The model presented below describes the choice of a firm which makes use of temps in order to adjust its labor force to fluctuations in demand. In

\footnotetext{
${ }^{6}$ Bronstein (1991), reviewing employer surveys for Western Europe, indicates three main motivations: performance of occasional jobs or peak activity; temporary replacement; prospecting among temporary workers for candidates to fill vacancies on a permanent basis. According to a survey conducted by Abraham (1988) in the US, among firms using temporary help employees, $79 \%$ declared at least one motivation that might be put under the broad heading of variability in demand. Atkinson et al. (1996) report a survey for the UK, where firms indicated the following reasons to hire temps (multiple answers allowed): matching peaks in demand (63.3\%); covering holidays/sick leave $(59.4 \%)$; performing oneoff tasks (39\%); trial for permanent work (20.2\%); other. Houseman (2001) presents an employer survey for the US where the most frequently cited reasons are: to provide assistance at times of unexpected increases in business (52\%); to fill a vacancy until a regular employee is hired (47\%); to cover holiday/sick leave (47\%); to screen candidates for regular jobs (21\%). A survey for Italy (Confinterim, 2000) reports three reasons: peak activity (70\%); replacement (18\%); expertise not available within the firm $(12 \%)$.
} 
this secondary sector of the labor market, the firm is assumed to have all bargaining power, i.e., it can determine both contract duration and wage. The trade-off arising in the firm's choice of contract length is the following. On one hand, an increase of contract duration produces an expected gain: it allows the firm to sidestep the investment in specific training, needed to insert a new temp in the production process, if the positive shock is still there in the immediate future and the old worker is no longer available (option value of contract length). On the other hand, an increase of contract duration is clearly associated with an expected loss: it forces the firm to pay the temp even when she/he is no longer useful, if the positive shock disappears. What follows is a simple formalization of such a trade-off.

Assume that the market demand a firm is facing evolves according to the stochastic process $D_{t}$ in discrete time. Demand can take only two values: high $\left(D_{H}\right)$, or normal $\left(D_{N}\right)$. For the firm, it makes sense to hire temporary agency workers ${ }^{7}$ only when demand is high. The temp's productivity is equal to $\theta$ in such a case, and zero otherwise. The firm's decision problem starts immediately after a positive shock is observed. At the beginning of such a period, the firm finds it profitable to hire a temp, who can be easily laid off when demand returns to its normal level, unlike the primary labor force associated to infinite firing costs.

For the sake of simplification, assume that the maximum allowed duration of a temporary contract is equal to two periods. Hence, after a positive shock pops up, the firm must choose whether to use the temp for only one period, or to offer her/him a two-period contract. The firm is risk-neutral and discounts future payoffs at the rate $\beta$. The worker is risk-adverse, with a reservation

\footnotetext{
${ }^{7}$ The number of workers needed by the firm during a positive non-permanent shock is exogenous and normalized to 1 .
} 
wage equal to: $\bar{w}=V^{-1}(\bar{u})$. The choice of the wage is fully determined by the worker's participation constraint. Assuming that the worker can break the contract in every period, the wage schedule is given by: $w_{t}=\bar{w}$.

Hiring a temp for the first time, the firm must bear a sunk cost $s$ in specific training or transaction costs. The sunk cost $s$ includes both the initial training cost necessary to teach the worker how to accomplish her/his new tasks and the reduction of worker's productivity during the initial fitting-in period (i.e., the period needed to insert her/him in the new working environment). The sunk cost $s$ might also incorporate a transaction cost component linked to the selection process. In every period, there is a probability $\lambda$ that the firm will not be able to find the same worker used in a previous assignment. To make the problem relevant, it is assumed that: $\bar{w}<\theta-\lambda s$.

Since we have set the maximum allowed contract length to be equal to two periods, we can at first assume that the process of market demand displays transitory shocks whose duration equals two periods as well. In particular, assume that there is a probability $\alpha$ that a positive shock pops up (i.e, that $\left.D_{t}=D_{H}\right)$, unless it has just occured in the previous period, in which case $D_{t}$ persists at its higher level with probability $\rho$. Hence, the memory of all positive shocks is simply equal to one period (and the parameter $\rho$ captures the degree of their persistence, while the parameter $\alpha$ captures the degree of volatility in market demand). Formally:

$$
\begin{gathered}
\operatorname{Pr}\left[D_{t}=D_{H} \mid D_{t-1}=D_{N}\right]=\alpha, \\
\operatorname{Pr}\left[D_{t}=D_{H} \mid D_{t-1}=D_{H}, D_{t-2}=D_{N}\right]=\rho, \\
\operatorname{Pr}\left[D_{t}=D_{H} \mid D_{t-1}=D_{H}, D_{t-2}=D_{H}\right]=\alpha .
\end{gathered}
$$

Given this simple setup, the next section identifies the optimal contract length chosen by the firm. 


\subsection{Optimal Contract Length}

The firm must choose whether to offer a short (one-period) contract or a long (two-period) one. The optimization problem starts any time a positive shock occurs and the previous contract has already expired, within an infinite time horizon. Because of the stationarity of the problem, if a given contract length is optimal at time $t$, conditioning on the observed state of market demand, it is optimal at time $t+2$ too. Since no decision is actually associated with the state of normal demand, where temps are not productive, $D_{N}$ is an absorbing state. Defining $V_{i}$ as the value function associated to $D_{i}(i=H, N)$, we have:

$$
V_{N}=\frac{\beta \alpha V_{H}}{1-\beta(1-\alpha)}
$$

The value function $V_{H}$ obviously depends on the duration of the contract chosen by the firm $(\tau)$ :

$$
\begin{gathered}
V_{H, \tau=1}=(\theta-\bar{w}-\lambda s)+\beta \rho(\theta-\bar{w}-\lambda s)+\beta^{2}\left[\alpha V_{H, \tau=1}+(1-\alpha) V_{N}\right], \\
V_{H, \tau=2}=(\theta-\bar{w}-\lambda s)+\beta(\rho \theta-\bar{w})+\beta^{2}\left[\alpha V_{H, \tau=2}+(1-\alpha) V_{N}\right] .
\end{gathered}
$$

Both expressions can be rewritten as:

$$
\begin{gathered}
V_{H, \tau=1}=\Pi[\theta-\bar{w}-\lambda s+\beta \rho(\theta-\bar{w}-\lambda s)], \\
V_{H, \tau=2}=\Pi[\theta-\bar{w}-\lambda s+\beta(\rho \theta-\bar{w})],
\end{gathered}
$$

where $\Pi=[\beta \alpha+(1-\beta)] /[\beta \alpha(1-\beta)+1-\beta]$. Hence, the firm chooses a longer contract $(\tau=2)$ if and only if the following condition is satisfied:

$$
\rho \lambda s \geq(1-\rho) \bar{w} .
$$

The left-hand side of this condition represents the gain associated with a one-period increase of contract length (specifically, the expected saving 
in specific training or transaction costs). This expected saving comes from the option value of contract duration. The right-hand side represents the loss associated to a one-period increase of contract length (i.e., the expected wage loss if worker's productivity falls to zero). It is easy to see that the optimal level of contract length is increasing in $s, \lambda$ and $\rho$, and decreasing in $\bar{w}$. These results are very intuitive: an increase of $\lambda$ (or $s$ ) raises the marginal benefit of extending $\tau$ by one period; an increase of $\bar{w}$ raises the marginal cost; an increase of $\rho$ both raises the marginal benefit and lowers the marginal cost.

The volatility parameter $\alpha$ influences the expected payoffs of the firm by affecting the timing/discounting of the start of a new optimization decision, but it has no effect on the optimal contract length, since the memory of a positive shock and the maximum contract duration are assumed to be equal. The next section investigates what happens if this assumption is relaxed.

\subsection{A Possible Extension}

The quite intuitive results of the previous section are derived under the assumption that the maximum contract length is equal to the duration of a single shock. This is not an implausible hypothesis in our setting, since in Italy THE contracts cannot last more than 24 months, and it is unlikely that a transitory shock is going to affect production for more than two years. However, it might still be the case that a shock vanishes in less than 24 months. In our theoretical framework, for instance, we could assume that the memory of $D_{t}$ is still equal to two periods, but the maximum contract length is equal to three periods. How would this affect the results?

The value functions associated to the one-period and the two-period contract are the same as before:

$$
V_{H, \tau=1}=(\theta-\bar{w}-\lambda s)+\beta \rho(\theta-\bar{w}-\lambda s)+\beta^{2}\left[\alpha V_{H, \tau=1}+(1-\alpha) V_{N}\right]
$$




$$
V_{H, \tau=2}=(\theta-\bar{w}-\lambda s)+\beta(\rho \theta-\bar{w})+\beta^{2}\left[\alpha V_{H, \tau=2}+(1-\alpha) V_{N}\right] .
$$

But now, when a positive shock pops up, the firm may also find it optimal to choose the three-period contract. In such a case, since the memory of the demand process and the expiration of each contract are no longer synchronized, the notation becomes cumbersome. However, we can express the lifelong payoff associated to the three-period contract as:

$$
\begin{aligned}
V_{H, \tau=3}= & K_{0}+\beta^{3}\left\{\alpha(1-\rho) V_{N}+\alpha(1-\alpha) V_{H, \tau=3}+(1-\alpha)^{2} V_{N}+\alpha \rho K_{1}\right\} \\
+ & \beta^{3}\left\{\sum_{i=1}^{\infty} \beta^{3 i}[\alpha \rho(1-\alpha)] K_{1}+\sum_{i=1}^{\infty} \beta^{3 i}\left[\alpha^{2}+\alpha(1-\alpha)^{2}\right] V_{H, \tau=3}\right. \\
& \left.+\sum_{i=1}^{\infty} \beta^{3 i}\left[\alpha(1-\alpha)+(1-\alpha)^{3}+\alpha(1-\alpha)(1-\rho)\right] V_{N}\right\}
\end{aligned}
$$

where $K_{0}=(\theta-\bar{w}-\lambda s)+\beta(\rho \theta-\bar{w})+\beta^{2}(\alpha \theta-\bar{w})$, and $K_{1}=(\theta-\bar{w}-$ $\lambda s)+\beta(\alpha \theta-\bar{w})+\beta^{2}(\alpha \rho \theta+(1-\alpha) \alpha \theta-\bar{w})$. At the end of every three-period contract, the firm may find itself in three different situations: a) facing a state of normal demand $\left(V_{N}\right)$; b) facing a state of high demand as if it popped up for the first time $\left(V_{H, \tau=3}\right)$; c) entering a de-synchronized contract in a state of high demand that is produced by the persistence of an old shock, and is associated to the payoff $K_{1}$. These different paths develop up to infinity. Knowing that $V_{N}=\left[\beta \alpha V_{H}\right] /[1-\beta(1-\alpha)]$ and $\sum_{i=1}^{\infty} \beta^{3 i}=1 /\left[1-\beta^{3 i}\right]$, we can retrieve the values of $V_{H, \tau=i}$, with $i=1,2,3$.

Assume that $\tau=i$ is the optimal choice for the firm if and only if: $V_{H, \tau=i} \geq V_{H, \tau=j}>V_{H, \tau=k}$, for $i \neq j \neq k$. Although its simplicity, it is not possible to get analytical results for this problem. However, by means of numerical simulations, it is possible to show that the same comparative statics results of the previous section hold in this modified setting.

In Figures 1 through 6, some numerical simulations are displayed. In particular, these figures summarize the effects of the parameters $\rho, \lambda$, and 
$\alpha$ on the optimal contract length chosen by the firm. Each figure reports contract length in the vertical axis, and the parameter whose effect we are summarizing in the horizontal axis ( $\rho$ in Figure 1 and Figure $2 ; \lambda$ in Figure 3 and Figure $4 ; \alpha$ in Figure 5 and Figure 6). Letting each parameter vary smoothly in a given interval of variation, and conditioning on a predetermined set of all the other relevant parameters, the optimal contract length is calculated as discussed above in this section. Many other simulations have been performed, but all of them convey the same qualitative results of these figures, which are showed as representative examples.

The parameter $\rho$ has a positive effect (if any) on contract duration (see Figure 1 and Figure 2). The parameter $\lambda$ has a positive effect (if any) on contract duration (see Figure 3), even though situations where $\lambda$ does not influence duration - and the result is fully determined by the configuration of the other parameters - are very frequent (see Figure 4). The parameter $\alpha$ has a nonlinear effect (if any) on contract length (see Figure 5 and Figure 6). At low values of $\alpha$, contract length is increasing in this parameter. At high values of $\alpha$, the opposite happens.

\section{Econometric Analysis}

\subsection{Data}

The above theoretical framework uses an option-value argument to find a positive effect of the degree of serial correlation of market demand $(\rho)$ on THE contract length. Longer contracts have an option value, since they can be used to sidestep (or postpone) the sunk cost due to the selection and training of temps. A crucial feature of this argument is that the firm may not be able to re-hire a worker previously used in a short-term assignment $(\lambda \neq 0)$. In 
this section, we identify two empirical counterparts of the parameters $\rho$ and $\lambda$, and estimate their association with the observed contract duration of Italian temporary agency workers.

The analysis makes use of the national data set of "Manpower", an international firm operating in the sector of THE and one of the main companies in the recently born Italian market. The market share of "Manpower" in Italy is around $25 \%$ and its agencies are distributed across all regions. The data set contains the individual characteristics of all temps employed by "Manpower" agencies. The following personal details of each worker are reported: gender; age; place of residence; marital status; nationality; occupation profile (blue collar or white collar). The data set contains the number and time-length of temporary assignments, as well as the economic sector and geographical location of the client firms that used the workers. Unfortunately, the data set does not report workers' wages. However, it should be noted that, in the Italian institutional setting, a firm cannot offer different wages to two temps belonging to the same category (as specified by collective agreements) simply because it is offering them different contract durations. In this context, we do not expect wage determination to affect individual contract length.

The data set considers all the workers sent to temporary assignments. The starting dates of recorded assignments range from February 1998 to December 2001; the number of temporary workers is 111,161; the number of using firms is 23,027; the total number of signed contracts is 197,953. Table 1 reports some descriptive statistics of the individual characteristics of temporary workers employed by "Manpower", and compares them to the characteristics of either temps from other agencies or permanent workers. All variables but age and the waiting period (i.e., the period from the enrollment in the agency list to the first assignment) are dummies. The representative temp is 
young (the average age is 28.7$)$, single (79 percent), male (62 percent), and blue collar (72 percent). The vast majority of workers is Italian, although 11 percent of them have a different nationality. If we classify workers according to the broad sector of the economy or their geographical location, we see that "Manpower" temps are prevalently from the North of the country (60 percent) and employed in the manufacturing sectors (75 percent). The figures for using firms instead of workers are slightly different (see Table 2): 73 percent in the manufacturing sector and 70 percent from the North. This means that manufacturing firms are not only the lion's share of those using temps, but they also use this new form of employment more frequently than other firms. Firms from the South use THE intensively (15 percent), even though they are a small fraction of total firms (3 percent).

\subsection{Testing Model's Predictions}

In order to test the persistence effect, we must choose how to estimate the degree of serial correlation of economic activity in each industry. Considering the available data, the monthly index of industrial production can be used in this respect. In fact, this index is available for all the 9 manufacturing sectors recorded in the "Manpower" data set (see Istat, "Conti trimestrali"). ${ }^{8}$ The fact that only manufacturing sectors are considered is not a great limitation, since - as shown in Table 1 - the vast majority of Italian temps is employed in those industries. In each sector, the index displays a clear time trend, as well as seasonal patterns. Hence, we first detrend and deseasonalize it, and then estimate an autoregressive process of order one. The industry-specific autocorrelation parameter (PERS) can be used as a proxy of the persistence

\footnotetext{
${ }^{8}$ The 9 sectors are: food/beverage/tobacco; textiles; wood/paper; chemicals; non-metal minerals; metals; energy; machinery/electronics; transportation manufacturing.
} 
of production away from its normal level. The values of PERS for the period of the "Manpower" data set average 0.16 in the available sectors, with a standard deviation equal to 0.12 .

To test whether volatility has a separate effect on contract length, we could also consider the variance of industrial production (VOL), whose values average 90 with a standard deviation equal to 25.1. At the end, since we are disregarding workers in service or other sectors, as well as workers with missing values in relevant variables, the final sample used for the econometric analysis contains 55,204 observations.

In order to test the effect of market tightness (i.e., the effect of the probability of not finding a worker previously used in a temporary assignment), we can use a measure derived directly from the "Manpower" data set, such as the province-specific average waiting time in the agency list (WAIT). This is the average period that elapses from the worker's enrollment in a "Manpower" agency to the day he/she gets the first contract. Assuming that the province represents the reference labor market of firms, the higher the time that workers spend in the agency list without any assignment, the lower the probability of not finding a specific worker. In the final sample, the values of WAIT, in the 101 provinces where "Manpower" using firms are located, average 138.1 (days) with a standard deviation equal to 51.8 .

The dependent variable of the analysis is the duration of a single contract. In the final sample, the average duration is equal to 61.9 days (with a standard deviation equal to 76), while the median duration is 34 days. The distribution of observed contract length is positively skewed. A semilog specification seems appropriate. Hence, the dependent variable used in the following analysis is the log of contract duration (DUR). 
Concerning the econometric specification, duration techniques are not appropriate, as one could think at first. The dependent variable is the duration agreed upon at the signing of the contract, depending on the worker's and firm's characteristics at that point. Premature separations are not observed. Using standard regression techniques, however, we must be aware of the problem caused by the merging of micro and aggregate data (Kloek, 1981; Moulton, 1990). The specification must incorporate the fact that disturbances are correlated within groups. It is reasonable to expect that units within the same industry and/or within the same province share some unobservable characteristics that lead the regression disturbances to be correlated. Failure to incorporate group effects may produce a large downward bias in the standard errors, especially if the effects of interest have to be estimated using between-group variation.

Hence, we estimate the following error components model, for worker $i$ and cluster $c$ :

$$
D U R_{i c}=x_{i c}^{\prime} \beta+\alpha P E R S_{c}+\gamma W A I T_{c}+\pi V O L_{c}+u_{c}+\epsilon_{i c}
$$

where the x's vary within the cluster, while the variables of interest (PERS, WAIT, VOL) are common to all workers in the cluster. The regression error term is the sum of a cluster component $u_{c}$ and an individual component $\epsilon_{i c}$. We assume that the errors are equicorrelated within each cluster, while they are uncorrelated between clusters. Our clusters are represented by the full set of interactions between the 9 industry dummies and the 101 province dummies. This means that there are 909 possible clusters. However, since in some provinces not all the manufacturing sectors are observed, the workers in the final sample can be partitioned in 537 distinct clusters. 
There are two general ways to estimate the above equation: 1) OLS with adjusted standard errors, so as to incorporate the within-industry correlation of disturbances; 2) random-effect panel estimation. In turn, one can adjust OLS standard errors using either the method developed by Liang and Zeger (1986), more commonly known as the Stata cluster command, or the correction formula proposed by Moulton (1986). ${ }^{9}$ It is usually pointed out that the first method is reliable only when the number of clusters is large, ${ }^{10}$ but this does not represent a problem in our setting.

Table 3 reports the estimation results. In columns (1) through (4), the volatility measure VOL is included among the regressors, while it is excluded in the remaining columns. Columns (1) and (5) report OLS estimates with naive standard errors, just as a reference. Columns (2) and (6) report OLS estimates with Stata-corrected standard errors. Columns (3) and (7) report OLS estimates with Moulton-corrected standard errors. Columns (4) and (8) report the results of maximum-likelihood random-effect regressions.

According to the OLS coefficients in columns (1) through (3), an increase of the persistence parameter (PERS) equal to its standard deviation produces, on average, a $12 \%$ increase of contract length. An increase in the workers' availability measure (WAIT) equal to its standard deviation is associated to a $36 \%$ drop in contract length. The volatility index (VOL) displays

\footnotetext{
${ }^{9}$ The Moulton factor used to correct OLS standard errors is given by:

$$
\frac{V(\widehat{\beta})}{V_{0}(\widehat{\beta})}=1+\left[\frac{V\left(n_{s}\right)}{\bar{n}}+(\bar{n}-1)\right] \rho_{X} \rho
$$

where $\widehat{\beta}$ is the OLS slope coefficient estimator of the regressor $X ; \frac{V(\widehat{\beta})}{V_{0}(\widehat{\beta})}$ the ratio of the true variance of the estimator to its misspecified variance; $n_{s}$ the size of group $s ; \bar{n}$ the average group size; $\rho_{X}$ the intraclass correlation of the regressor $X ; \rho$ the intraclass correlation of disturbances (under the assumption that errors are equicorrelated within groups). This formula highlights why the clustering problem is particularly harsh when looking at cluster-specific regressors, since for them $\rho_{X}=1$.

${ }^{10}$ See Donald and Lang (2004) for a comparison between Stata and Moulton correction.
} 
a positive coefficient too, but it is never significantly different from zero in the specifications that take into account clustering. ${ }^{11}$

A comparison of the significance of the estimates in Table 3 points out that it is indeed very important to control for clustering, in order to draw the right inference. However, the parameters associated to the two variables of interest (PERS and WAIT) are quite robust with respect to the econometric strategy we implement. With the Stata-adjusted standard errors, the effect of production persistence is significant at a $5 \%$ level, and the availability effect at a $1 \%$ level. With the more demanding Moulton correction, the former is no longer significantly different from zero, while the latter is still significant (1\% level). In the random-effect regression, the availability effect is only borderline significant ( $10 \%$ level), while the effect of persistence is different from zero at a $1 \%$ level.

To sum up, the empirical evidence presented in this section is consistent with the two main implications of the simple theoretical model presented in Section 3. Contract length is longer in sectors that experience a greater persistence of production shocks. Contract length is lower where it is easier to find again a worker previously used in a THE assignment.

\section{Conclusion}

This paper has investigated the determinants of the duration of THE contracts. In order to highlight the relevant trade-off in the firm's choice of assignment durations, a very simple theoretical model has been developed in Section 3. The model has two testable implications. First, the serial correlation of market demand positively influences contract length, because of an

\footnotetext{
${ }^{11}$ Also the inclusion of the squared volatility index as an additional regressor produced a non-significant coefficient.
} 
option-value argument: assuming that the hiring of a new temp is associated with selection and training costs, longer contracts have an option value in the face of a greater persistence of shocks. Second, the shortage of alternative employment opportunities negatively influences contract length, since the option value of duration is reduced by the greater probability of finding a worker previously used in a THE assignment.

Using data on the temporary workers hired by one of the leading THE companies in Italy, both implications are confirmed by the econometric analysis in Section 4, even after a careful control of the plausible within-industry and within-province correlation of disturbances. The industry-specific persistence of production shocks is positively correlated with contract length. On the contrary, the province-specific waiting time in the list of THE agencies is negatively correlated with contract length.

Since contract duration turns out to be a good proxy of workers' precariousness in this kind of non-standard relationship, temporary agency workers are clustered according to the above two measures, and - in a sense - they are "less temporary" both in industries with a higher persistence of shocks (where the "intertemporal" demand for them is higher) and in tighter local labor markets (where their "intertemporal" supply is less elastic). 


\section{References}

ATKINSON J., RICK J., MORRIS S. and WILLIAMS M. (1996), Temporary work and the labour market, Report 311, The Institute for Employment Studies, Brighton

AUTOR D.H. (2001), "Why Do Temporary Help Firms Provide Free General Skills Training?", in The Quarterly Journal of Economics, 116 (4)

AUTOR D.H. (2003), "Outsourcing at Will: The Contribution of Unjust Dismissal Doctrine to the Growth of Employment Outsourcing", in Journal of Labor Economics, 21(1)

BRONSTEIN A.S. (1991), "Temporary Work in Western Europe: Threat or Complement to Permanent Employment?", in International Labour Review, 3, 291-310

CONFINTERIM (2000), Il lavoro temporaneo, Milano

DANZIGER L. (1988), "Real Shocks, Efficient Risk Sharing, and the Duration of Labor Contracts", in The Quarterly Journal of Economics, 103, $435-440$

DONALD S.G. and LANG K. (2004), Inference with Difference in Differences and Other Panel Data, mimeo, Boston University

DYE R.A. (1985), "Optimal Length of Labor Contracts", in International Economic Review, 26, 1, 251-270

ESTEVAO M. and LACH S. (1999), The Evolution of the Demand for Temporary Help Supply Employment in the United States, NBER Working Paper n.7427

GRAY J.A. (1978), "On Indexation and Contract Length", in Journal of Political Economy, 86, 1-18

HARRIS M. and HOLMSTROM B. (1987), "On the Duration of Agreements", in International Economic Review, 28, 2, 389-406

HOUSEMAN S.N. (2001), "Why Employers Use Flexible Staffing Arrangements: Evidence from an Establishment Survey", in Industrial and Labor Relations Review, October 2001 
HOUSEMAN S.N. and OSAWA M. (eds) (2003), Nonstandard Work in Developed Economies: Causes and Consequences, W.E. Upjohn Institute for Employment Research

ICHINO A., MEALLI F. and NANNICINI T. (2005), "Temporary Work Agencies in Italy: A Springboard Toward Permanent Employment?", in Giornale degli Economisti e Annali di Economia, 64(1), 1-27

ISFOL (2001), Il lavoro interinale. Prima ricerca nazionale sui dati dei Centri per l'impiego, Roma.

KLOEK T. (1981), "OLS Estimation in a Model where a Microvariable is Explained by Aggregates and Contemporaneous Disturbances are Equicorrelated", in Econometrica, 49, 1, 205-207

KVASNICKA M. (2005), Does Temporary Agency Work Provide a Stepping Stone to Regular Employment?, Collaborative Research Center 649 Discussion Paper, 48/2005

LECHNER M., ALMUS M., PFEIFFER F. and SPENGLER H. (2001), "The Impact of Non-profit Temping Agencies on Individual Labour Market Success in the West German State of Rhineland-Palatinate", in LECHNER M. and PFEIFFER F. (eds), Econometric Evaluation of Labour Market Policies, Heidelberg: Physica/Springer, 211-242

LIANG K. and ZEGER S.L. (1986), "Longitudinal Data Analysis Using Generalized Linear Models", in Biometrika, 73, 13-22

MALO M.A. and MUNOZ-BULLON F. (2002), Temporary Help Agencies and the Labour Market Biography: A Sequence-Oriented Approach, FEDEA, EEE n. 132

MINISTERO DEL LAVORO (2000), Rapporto di monitoraggio sulle politiche occupazionali e del lavoro, N.2/2000, Roma

MONTANINO A. and SESTITO P. (2003), "Le molte funzioni del lavoro interinale in Italia: da strumento di flessibilit a contratto di prova", in Rivista di Politica Economica, marzo-aprile 2003

MOULTON B.R. (1986), "Random Group Effects and the Precision of Regression Estimates", in Journal of Econometrics, 32, 385-397 
MOULTON B.R. (1990), "An Illustration of a Pitfall in Estimating the Effects of Aggregate Variables on Micro Units", in The Review of Economics and Statistics, 334-338

MURPHY K. (1992), "Determinants of Contract Duration in Collective Bargaining Agreements", in Industrial and Labor Relations Review, 45, 352365

NANNICINI T. (2004), The Take-Off of Temporary Help Employment in the Italian Labor Market, ECO-EUI Working Paper n.9/04

OECD (2002), Taking the measure of temporary employment, in Employment Outlook, Paris

PIORE M. (1980), "Dualism as a Response to Flux and Uncertainty", in BERGER S. and PIORE M. (eds), Dualism and Discontinuity in Industrial Society, Cambridge University Press

RUSSO G., GORTER C. and MOOLENAAR D. (1997), "Lavori temporanei e lavoratori temporanei: l'esperienza olandese", in Lavoro e relazioni industriali, 2, 61-94

SAINT-PAUL G. (1996), Dual Labor Markets, MIT Press

SEGAL L.M. and SULLIVAN D.G. (1997a), Temporary Services Employment Durations: Evidence from State UI Data, WP-97-23, Federal Reserve Bank of Chicago

SEGAL L.M. and SULLIVAN D.G. (1997b), "The Growth of Temporary Services Work", in Journal of Economic Perspectives, 11, 2, 117-136

VROMAN S. (1989), "Inflation Uncertainty and Contract Duration", in Review of Economics and Statistics, 71, 677-681

WALLACE F. and BLANCO H. (1991), "The Effects of Real and Nominal Shocks on Union-Firm Contract Duration", in Journal of Monetary Economics, 27, 361-380 


\section{Tables and Figures}

Table 1: The characteristics of "Manpower" temporary workers

\begin{tabular}{lccc}
\hline \hline & "Manpower" & Other Agencies & Permanent \\
\hline Male & 0.62 & 0.62 & 0.63 \\
Age & 28.7 & 27.7 & 39.6 \\
Single & 0.79 & - & - \\
Italian & 0.89 & - & - \\
Blue collar & 0.72 & - & - \\
Waiting period & 70.6 & - & - \\
Contract length & 57.7 & 42.2 & - \\
\hline North & 0.60 & 0.63 & 0.52 \\
Center & 0.25 & 0.25 & 0.20 \\
South & 0.15 & 0.12 & 0.28 \\
\hline Manufacturing & 0.75 & 0.64 & 0.41 \\
Services & 0.23 & 0.18 & 0.46 \\
Other sectors & 0.02 & 0.18 & 0.13 \\
\hline \hline
\end{tabular}

Sources: first column from "Manpower" data set; second column from Confinterim (2000); third column from Ministero del lavoro (2000). Note for "Manpower" data set: 111,161 workers. All variables are dummies, except age (in years), contract lenght (in days), and the waiting period in the agency's list before the first contract (in days).

Table 2: The characteristics of "Manpower" using firms

\begin{tabular}{lc}
\hline \hline & "Manpower" \\
\hline North & 0.70 \\
Center & 0.27 \\
South & 0.03 \\
\hline Manufacturing & 0.73 \\
Services & 0.25 \\
Other sectors & 0.02 \\
\hline \hline
\end{tabular}

Note: 23,027 firms. All variables are dummies. 
Table 3: The effects of persistence, volatility, and market tightness

\begin{tabular}{lcccccccc}
\hline \hline & $(1)$ & $(2)$ & $(3)$ & $(4)$ & $(5)$ & $(6)$ & $(7)$ & $(8)$ \\
& DUR & DUR & DUR & DUR & DUR & DUR & DUR & DUR \\
\hline PERS & .9330 & .9330 & .9330 & .6270 & .6397 & .6397 & .6397 & .5843 \\
& $(.0577)$ & $(.3835)$ & $(.7234)$ & $(.1873)$ & $(.0474)$ & $(.3724)$ & $(.5939)$ & $(.1787)$ \\
WAIT & -.0070 & -.0070 & -.0070 & -.0012 & -.0070 & -.0070 & -.0070 & -.0012 \\
& $(.0001)$ & $(.0027)$ & $(.0017)$ & $(.0007)$ & $(.0001)$ & $(.0027)$ & $(.0017)$ & $(.0007)$ \\
VOL & .0026 & .0026 & .0026 & .0008 & & & & \\
& $(.0003)$ & $(.0024)$ & $(.0038)$ & $(.0010)$ & & & & \\
male & .0754 & .0754 & .0754 & -.0102 & .0884 & .0884 & .0884 & -.0099 \\
& $(.0146)$ & $(.0638)$ & $(.0777)$ & $(.0141)$ & $(.0145)$ & $(.0614)$ & $(.0771)$ & $(.0141)$ \\
age & .0075 & .0075 & .0075 & .0066 & .0077 & .0077 & .0077 & .0066 \\
& $(.0009)$ & $(.0023)$ & $(.0030)$ & $(.0009)$ & $(.0009)$ & $(.0023)$ & $(.0030)$ & $(.0009)$ \\
single & -.1222 & -.1222 & -.1222 & -.0687 & -.1220 & -.1220 & -.1220 & -.0686 \\
& $(.0165)$ & $(.0287)$ & $(.0461)$ & $(.0155)$ & $(.0166)$ & $(.0285)$ & $(.0462)$ & $(.0155)$ \\
italy & -.1522 & -.1522 & -.1522 & -.1406 & -.1572 & -.1572 & -.1572 & -.1406 \\
& $(.0178)$ & $(.0527)$ & $(.0877)$ & $(.0178)$ & $(.0178)$ & $(.0519)$ & $(.0877)$ & $(.0178)$ \\
blue & -.2822 & -.2822 & -.2822 & -.3193 & -.2695 & -.2695 & -.2695 & -.3191 \\
& $(.0193)$ & $(.0687)$ & $(.1093)$ & $(.0187)$ & $(.0194)$ & $(.0741)$ & $(.1098)$ & $(.0187)$ \\
partime & -.3104 & -.3104 & -.3104 & -.1712 & -.2962 & -.2962 & -.2962 & -.1711 \\
& $(.0300)$ & $(.0898)$ & $(.1324)$ & $(.0275)$ & $(.0300)$ & $(.0901)$ & $(.1326)$ & $(.0275)$ \\
\hline \hline
\end{tabular}

Note: 55,204 observations. PERS is the sector-specific estimated persistence of industrial production; WAIT is the province-specific average time workers spend in the agency's list before their first contract; VOL is the sector-specific variance of industrial production. All control covariates are dummies (except age). Columns (1) and (5): OLS with naive standard errors. Columns (2) and (6): Stata correction. Columns (3) and (7): Moulton correction. Columns (4) and (8): maximum-likelihood random effect. 
Figure 1

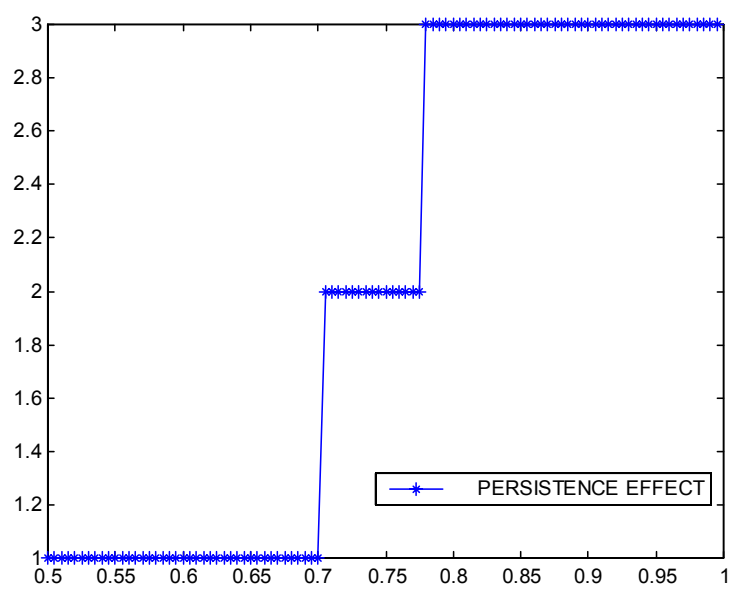

$\theta=1000, w=500, s=300, \lambda=0.7, \alpha=0.7, \beta=0.8$

\section{Figure 3}

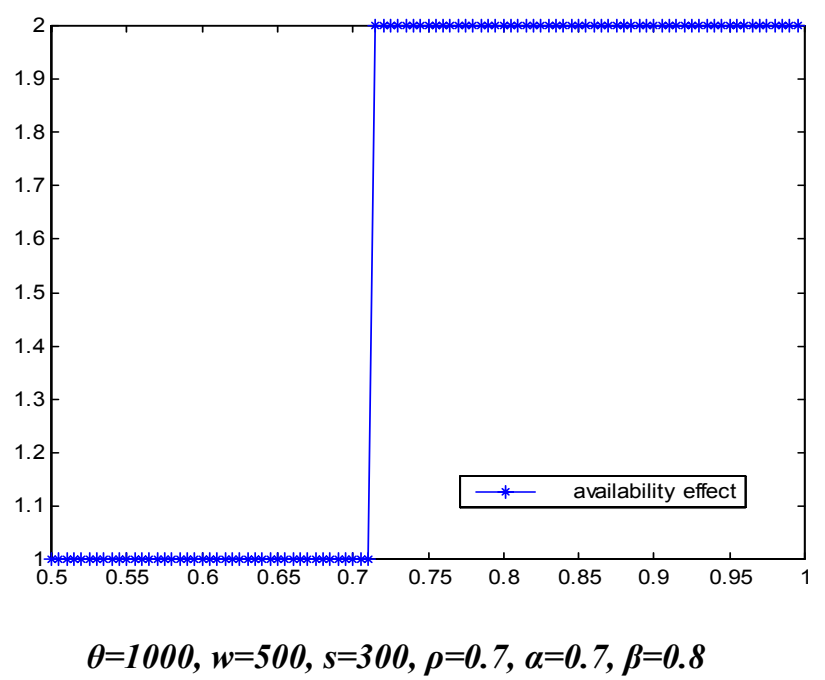

\section{Figure 5}

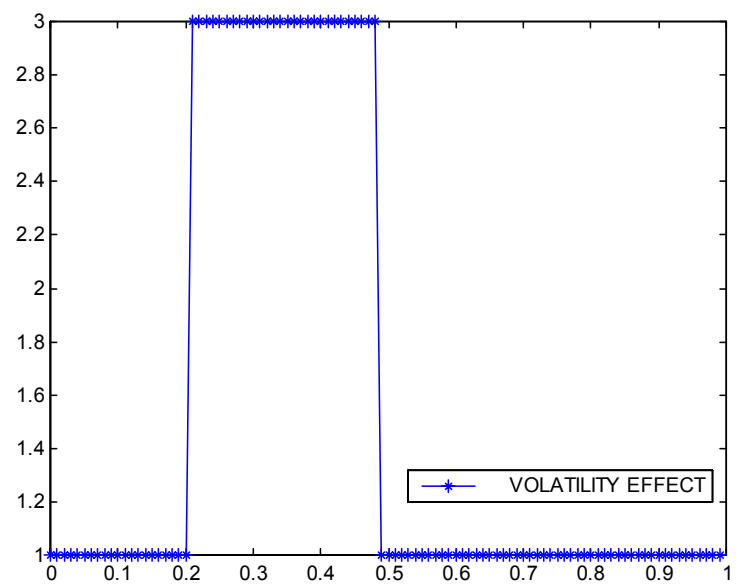

$\theta=1000, w=500, s=300, \rho=0.6, \lambda=0.8, \beta=0.8$
Figure 2

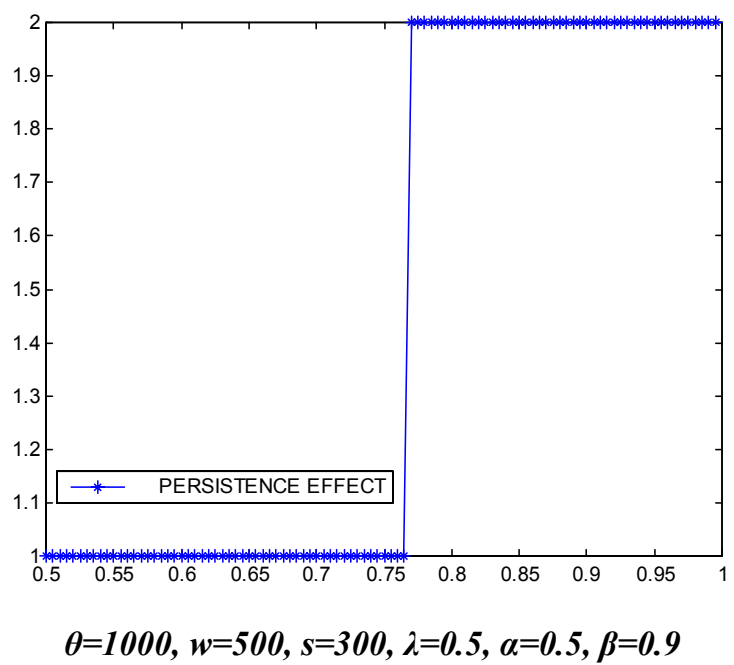

Figure 4

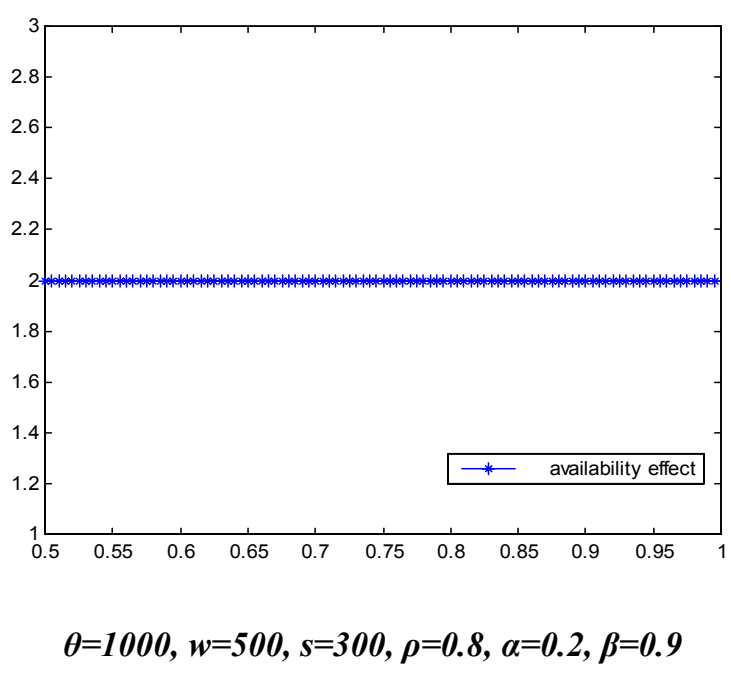

Figure 6

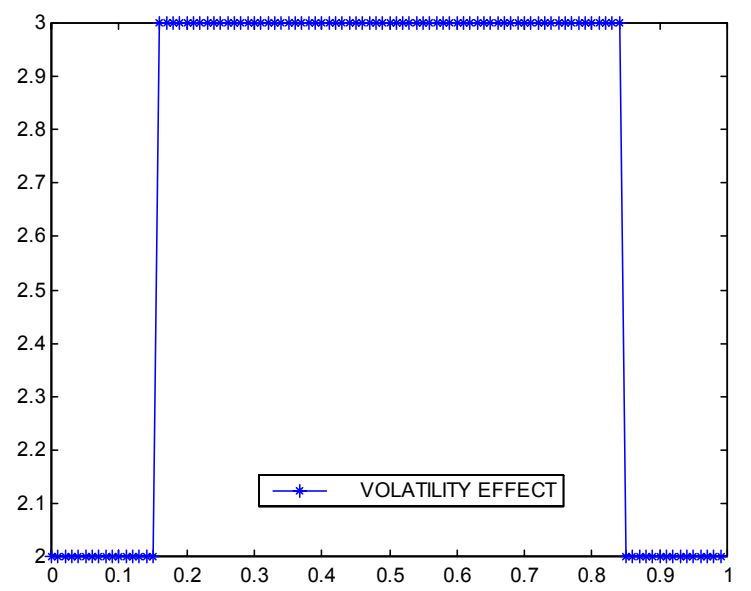

$\theta=1000, w=500, s=300, \rho=0.8, \lambda=0.2, \beta=0.9$ 